\section{Melkersson-Rosenthal syndrome}

Sir,

Melkersson-Rosenthal syndrome (MRS) is a very rare clinical entity. Its classical form is being characterized by following triad: Facial nerve palsy, swelling of lips, and fissured tongue. ${ }^{[1]}$ However, the monosymptomatic form is more common and typical manifestation is facial edema and/or enlargement of lips. ${ }^{[2]}$

A 34-year-old male presented with a history of acute onset weakness of right side of face with deviation of nasolabial fold to left with inability to close right eye and lost wrinkling on forehead for 3 days. He also complained of heaviness in right ear with decreased hearing in right ear for 2 days. He did not have any fever, otorrhea, vesicles on the ear, trauma, otalgia, vertigo, tinnitus or exposure to cold wind. He had a history of three episodes of similar weakness in the right side of his face before 9 years, 7 years and 3 years, which all had improved with treatment with steroids. He gave a history of being told to have Bell's palsy by three different physicians he had consulted each time. Each time he had improved after receiving short course of oral steroids. He did not have any other systemic disease and did not have decrease in hearing in the earlier episodes of similar complaints. None of his family members had similar complaints ever. He did not have any history to suggest any respiratory disease, gastrointestinal complaints, skin rash or nodule, and did not have any history of consumption of drugs known to cause angioedema like angiotensin-converting enzyme inhibitors, or any other medicines.
On examination, he had lower motor neuron type right facial paralysis associated with sensory-neural hearing loss in right ear with normal vision, smell, taste and normal sensations in the face. He was found to have facial and labial swelling in the right half his face and he had geographic tongue [Figure 1]. He had evidence of sensorineural deafness on the right side. On enquiring the patient about the facial edema and deafness, he reported that he had facial edema for one week and decreased hearing for 2 days. In addition to the facial, labial and tongue swelling, he also had gingival swelling and swelling of floor of mouth. He did not have any cobblestoning, staghorning, tissue tags or ulcers or cheilitis. He had a total site score of 6 and activity score of 5 based on King's College London orofacial granulomatosis (OFG) severity scoring. The rest of the neurologic examination, fundoscopy and external and middle ear examination were normal. His hemogram, erythrocyte sedimentation rate, renal, liver functions were normal. His antinuclear antibody (ANA) profile, serum anti-neutrophillic cytoplasmic antibody (ANCA), serum human immunodeficiency virus (HIV) and treponema pallidum hemagglutition (TPHA) did not reveal any abnormality. He did not have any clinical features to suggest sarcoidosis and his chest X-ray and serum angiotensin-converting enzyme level were normal. He did not have fever, parotitis or uveitis to suggest Heerfordt's syndrome. He did not have any gastrointestinal disturbances and his stool examination and per rectum examination were normal ruling out Crohn's disease. His cerebrospinal fluid examination was acellular with normal protein and sugar with normal cytology. His magnetic resonance imaging (MRI) brain revealed post contrast enhancement of the right facial nerve along the terminal part of its intracanalicular segment, labyrinthine segment and proximal part of mastoid segment on post-contrast volumetric

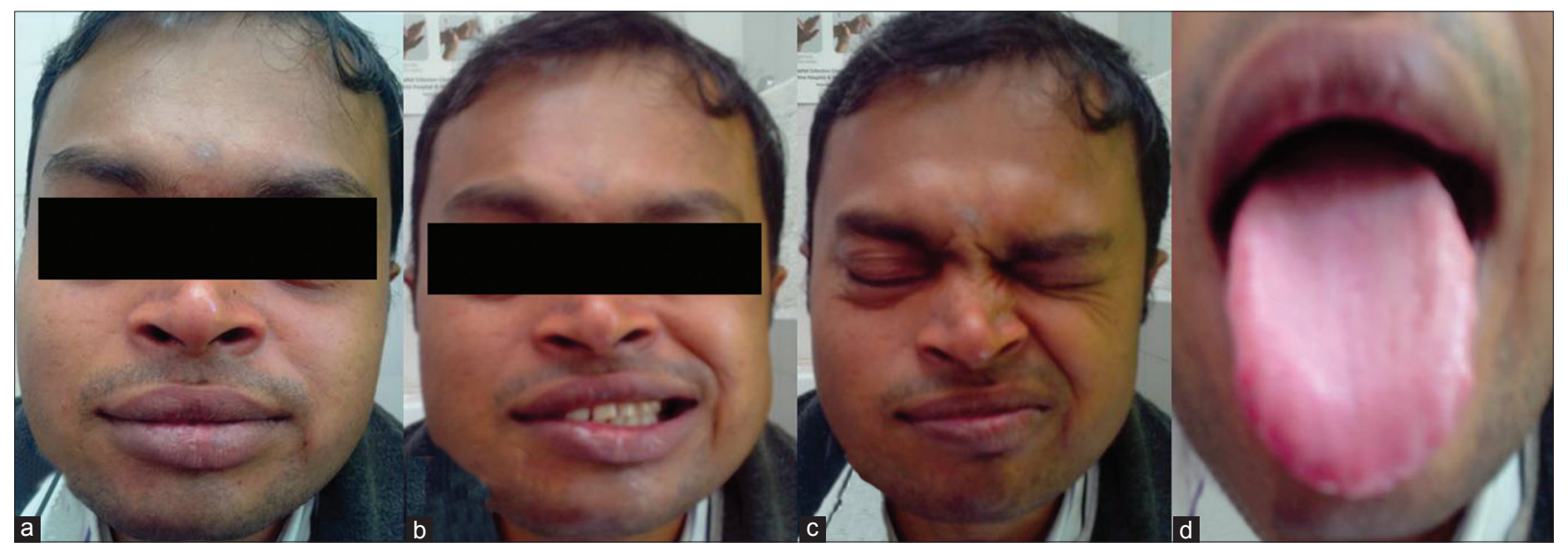

Figure 1: (a) Labial edema, (b and c) right lower motor neuron seventh nerve palsy with labial edema and periorbital edema on right side. (d) labial and tongue edema 


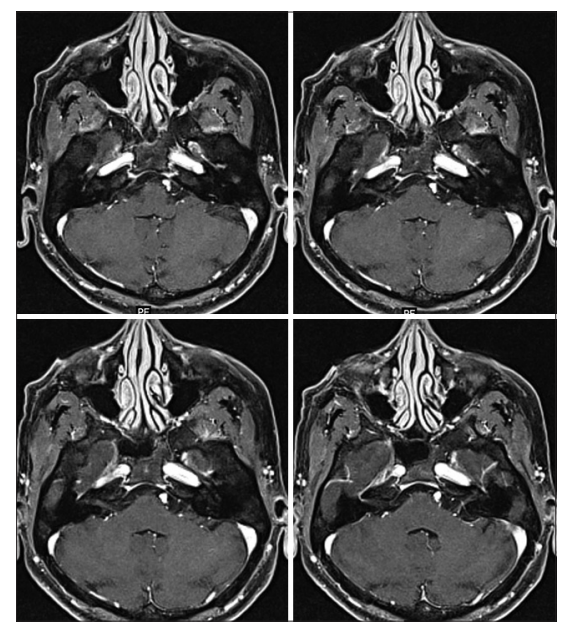

Figure 2: Post-contrast enhancement of the right facial nerve along the terminal part of its intracanalicular segment, labyrinthine segment and proximal part of mastoid segment on post-contrast volumetric interpolated brain examination (VIBE) T1 image sequences

interpolated brain examination (VIBE) T1 image sequences, see Figure 2.

He did not have any history suggesting use of any medicines repeatedly during each of these episodes and none of these episodes were associated with any of rash, itching, fever, diarrhea, vomiting or breathlessness. In all of the episodes, facial palsy was the most predominant symptom rather than orolabiofacial edema making the diagnosis of MRS more likely than idiopathic recurrent angiodema. Since in the past he had improved with empiric oral steroid only, he did not agree for labial deep biopsy to confirm the diagnosis microscopically. The patient was not affording testing for acquired $\mathrm{C} 1$ inhibitor deficiency, Herpes simplex and varicella zoster serology. He did not receive acyclovir in the previous episodes and did not have any history of facial vesicles in the past making herpes simplex or zoster unlikely. He was treated with prednisolone in a dose of $1 \mathrm{mg} / \mathrm{kg}$ for 2 weeks which was gradually tapered off over 3 weeks. Over the next 3 weeks he had complete improvement in his facial weakness, sensorineural deafness as well as facial edema.

MRS is a rare neurological entity of unknown etiology. Classical triad includes recurrent facial palsy, swelling of lips, and deep furrowed tongue (lingua plicata), sometimes known as scrotal tongue, but these classical findings are seen rarely. ${ }^{[3]}$ This entity is seen equally in both gender and has worldwide distribution. Due to inconsistency of signs and symptoms appearance and duration of symptoms, majority of patients go undiagnosed for long period of time, as long as for 30 years, and may eventually become permanent. ${ }^{[4]}$ Recurrent swelling of eyes and upper lip usually involves the same side. The facial palsy is of lower motor neuron type and can be mistaken clinically as Bell's palsy, can be unilateral or bilateral and of varying severity. Involvement of other cranial nerves also has been noted such as olfactory, auditory, glossopharyngeal and hypoglossal nerves ${ }^{[5]}$ Numbness can involve other body parts also. Our patient had evidence of sensory-neural deafness in association with facial palsy which recovered on treatment with steroids.

This syndrome was mistakenly believed to be manifested only in the whites. ${ }^{[6]}$ This is because most cases reported in the literature were from countries with predominantly white populations. Isolated cases have been reported in South Africa, ${ }^{[7]}$ middle east, ${ }^{[8]}$ India, ${ }^{[9]}$ Japan. ${ }^{[10]}$ Thus, it appears MRS has no racial predilection. It commonly occurs in second to fourth decade but few cases in pediatric age group as well as preadolescents have been reported.

Etiology and pathogenesis of MRS have not been fully determined. Several factors such as infections, autoimmunity, neurotropic factors, atopy, and hypersensitivity to food additives have been implicated in pathogenesis, but none have been clinically proven. ${ }^{[3,11]}$ Although not frequently proven, there is growing evidence that benzoate and cinnamon free diet helps in patients with MRS. Infections particularity oral herpes, oral candidiasis, mycobacterium leprae and lymphogranuloma venereum have been attributed to its genesis. DNA sequence study of MAP1S900 (Mycobacterium avium subspecies paratuberculosis (MAP)) has been found in few studies. ${ }^{[12,13]}$ Other etiologies under consideration are hypersensitivity, autoimmune factors and neurotrophic factors which lead to, vasomotor disturbances causing swelling and $7^{\text {th }}$ nerve compression leading to paralysis. Deficiency of complement C1-INH may be the etiological factor contributing to orofacial swelling. ${ }^{[14]}$ The histopathological examination of the swollen lip or facial tissues reveal edema, non-caseating epitheloid cell granulomas, multinucleated Langhans-type giant cells, perivascular mononuclear inflammatory infiltration, and fibrosis. ${ }^{[15]}$ Studies using lymphoscintigraphy have documented impaired lymphatic drainage from the swollen area in patients with MRS and the corresponding follow-up lymphoscintigraphy have demonstrated a restoration of lymphatic flow after clinical improvement suggesting that lymphatic pathology plays an important role in pathophysiology of chronic facial swelling in patients with MRS. ${ }^{[16]}$

Differential diagnosis of MRS includes thyroid orbitopathy, allergy, atopy, angioedema, bacterial, 
viral or filarial infections, systemic lupus erythematosus, dermatomyositis, bell's palsy, leprosy and rosacea. This syndrome of oral lesions with noncaseating granulomas has also been associated with many connective tissue or inflammatory diseases like Crohn's disease, sarcoidosis, saprodontia nd food and drug allergy. ${ }^{[17-19]}$

The treatment of MRS remains a challenge because of the unclear etiopathogenesis. Various therapeutic methods have been described. ${ }^{[20]}$ Corticosteroids are widely used; some authors recommend systemic corticosteroids while others did not observe success with systemic methylprednisolone therapy. ${ }^{[21]}$ Some authors even recommend topical, intralesional or subcutaneous corticosteroids. Intralesional triamclinolone has been reported to be efficient and safe in orofacial granulomatosis however its effect is unknown in patients with involvement of facial nerve palsy. ${ }^{[22]}$ Combination of steroids and minocycline, clofazamine, NSAIDs and thalidomide have also been suggested but the true benefits of these are not known. Surgical treatments suggested include reduction cheiloplasty, Z-plasty, wedge resections as well as decompression of the facial nerve in its entire intratemporal course. ${ }^{[21,23]}$

\section{Soaham Dilip Desai, Priyanka Dumraliya, Deepak Mehta ${ }^{1}$}

Departments of Neurology and ${ }^{1}$ Radiology, Pramukhswami Medical College and Shree Krishna Hospital, Gujarat, India

Address for correspondence: Prof. Soaham Dilip Desai, Room 119, Ramanbhai Gokal Privilege Centre, Shree Krishna Hospital, Karamsad - 388 325, Gujarat, India. E-mail: drsoahamdesai@yahoo.com

\section{References}

1. Ang KL, Jones NS. Melkersson-Rosenthal syndrome. J Laryngol Otol 2002;116:386-8.

2. Gonçalves DU, de Castro $\mathrm{MM}$, Galvão $\mathrm{CP}$, Brandão $\mathrm{AZ}$, de Castro MC, Lambertucci JR. Cheilitis granulomatosa associated with Melkersson-Rosenthal syndrome. Braz J Otorhinolaryngol 2007;73:132-3.

3. Marques C, Machado A, Baptista AP. Marcrochelititis and Melkersson-Rosenthal syndrome. Review of 19 cases. Acta Med Port 1994;7:533-40.

4. Gerressen M, Ghassemi A, Stockbrink G, Riediger D, Zadeh MD. Melkerrson-Rosenthal syndrome: Case report of a 30-year misdiagnosis. J Oral Maxillofacial Surg 2005;63:1035-9.

5. Zeng W, Geng S, Niu X, Yuan J. Complete Melkerrson-Rosenthal syndrome with multiple cranial nerve palsies. Clin Exp Dermatol 2010;35:272-4.

6. Williams PM, Greenberg MS. Management of cheilitis granulomatosa. Oral Surg Oral Med Oral Pathol 1991;72;436-9.
7. Graff-Radford SB. Melkersson-Rosenthal Syndrome. A review of the literature and case report. S Afr Med J 1981;60:71-4.

8. Bataineh AB, Pillai KG, Manson M, Abu al-Khail A. An unsual case of the Melkersson-Rosenthal syndrome. A case report. Oral Surg Oral Med Oral Pathol Oral Radiol Endod 1995;80:289-92.

9. Jain VK, Dixit VB, Kheterpal HM. Melkersson-Rosenthal syndrome: Two case reports. Ann Dent 1990;49;30-1, 45.

10. Kanoy Y, Shiohara T, Yagita A, Nagashima M. Treatment of recalcitrant cheilitis granulomatosa with metronidazole. J Am Acad Dermatol 1992;27:629-30.

11. Medeiros M Jr, Araujo MI, Guimarães NS, Freitas LA, Silva TM, Carvalho EM. Therapeutic response to thalidomide in melkersson-Rosenthal syndrome: A case report. Ann Allergy Asthma Immunol 2002;88:421-4.

12. Apaydin R, Bahadir S, Kaklikkaya N, Bilen N, Bayramgürler D. Possible role of mycobacterium tuberculosis complex in Melkerrson-Rosenthal syndrome demonstrated with Gen-Probe amplified mycobacterium tuberculosis direct test. Australas J Dermatol 2004;45:94-9.

13. Muellegger RR, Weger W, Zoechling N, Kaddu S, Soyer HP, El Shabrawi-Caelen L, et al. Granulomatous cheilitis and Borrelia burgdorferi: Polymerase chain reaction and serologic studies in a retrospective case series of 12 patients. Arch Dermatol 2000;136:1502-6.

14. D'Amore M, Lisi S, Sisto M, Cucci L, Dow CT. Molecular identification of mycobacterium avium subspecies paratuberculosis in an Italian patient with Hashimoto's thyroiditis and Melkerrson-Rosenthal syndrome. J Med Microbiol 2010;59:137-9.

15. Pisanty S, Sharav Y. The Melkersson-Rosenthal syndrome. Oral Surg Oral Med Oral Pathol 1969;27:729-33.

16. Nittner-Marszalska M, Krasnowska M, Solarewicz-Madejek K, Jedrzejuk D, Szuba A. Melkersson-Rosenthal syndrome: Lymphoscintigraphy-documented impairment and restoration of facial lymphatic drainage in the course of disease. Lymphology 2010;43:34-41.

17. Tadokoro T, Ozawa K, Muso Y, Ito H, Itami S, Yoshikawa K Melkersson-Rosenthal syndrome caused by saprodontia: A case report. J Dermatol 2003;30:679-82.

18. Ferro JM, Oliveira SN, Correia L. Neurologic manifestations of inflammatory bowel diseases. Handb Clin Neurol 2014;120:595-605.

19. White A, Nunes C, Escudier M, Lomer MC, Barnard K, Shirlaw P, et al. Improvement in orofacial granulomatosis on a cinnamon- and benzoate-free diet. Inflamm Bowel Dis 2006;12:508-14.

20. Stein SL, Mancini AJ. Melkersson-Rosenthal syndrome in childhood: Successful management with combination steroid and minocycline therapy. J Am Acad Dermatol 1999;41:746-8.

21. Dutt SN, Mirza S, Irving RM, Donaldson I. Total decompression of facial nerve for Melkersson-Rosenthal syndrome. J Laryngol Otol 2000;114:870-3.

22. Alajbeg I, Rogulj AA, Hutinec Z. Orofacial granulomatosis treated with intralesional triamcinolone. Acta Dermatovenerol Croat 2011;19:165-9.

23. Ziemssen F, Rohrbach JM, Scherwitz C, Denk PO. Plastic reconstructive correction of persistent orofacial swelling and swelling of the eyelids in Melkersson-Rosenthal syndrome. Klin Monbl Augenheilkd 2003;220:352-6.

\begin{tabular}{|l|l|}
\hline \multicolumn{2}{|c|}{ Access this article online } \\
\hline Quick Response Code: & \\
\hline$\square$ & Website: \\
\hline
\end{tabular}

